\title{
In vivo activation of gene transcription via oestrogen response elements by a raloxifene analogue
}

\author{
Cecilia Engdahl, Caroline Jochems, Jan-Åke Gustafsson ${ }^{1}$, Paul T van der Saag ${ }^{2}$, Hans Carlsten \\ and Marie K Lagerquist \\ Department of Rheumatology and Inflammation Research, Institute of Medicine, Sahlgrenska Academy at University of Gothenburg, Guldhedsgatan 10A, \\ 41346 Gothenburg, Sweden \\ ${ }^{1}$ Department of Biosciences and Nutrition at NOVUM, Karolinska Institute, Huddinge 17177, Sweden \\ ${ }^{2}$ Hubrecht Institute, Utrecht 3508 AD, The Netherlands \\ (Correspondence should be addressed to C Engdahl; Email: cecilia.engdahl@rheuma.gu.se)
}

\begin{abstract}
Raloxifene is a selective oestrogen receptor modulator with tissue-specific effects. The mechanisms behind the effects of raloxifene are partly unclear, and the aim of the present study was to investigate whether raloxifene can activate the classical oestrogen-signalling pathway in vivo in three known oestrogen-responsive organs, uterus (reproductive organ), bone (non-reproductive organ) and thymus (immune organ). For this purpose, we have used reporter mice with a luciferase gene under control of oestrogen-responsive elements (EREs), enabling detection of in vivo activation of gene transcription via the classical oestrogen pathway. Three-month-old ovariectomized ERE-luciferase mice were treated with the raloxifene analogue (LY117018), oestradiol $\left(\mathrm{OE}_{2}\right)$ or vehicle for 3 weeks. Luciferase activation was measured in bone, uterus and thymus, and compared to bone parameters, and uterus and thymus
\end{abstract}

weights. The raloxifene analogue affected bone mineral density (BMD) to the same extent as $\mathrm{OE}_{2}$, and both treatments resulted in increased luciferase activity in bone. As expected, $\mathrm{OE}_{2}$ treatment resulted in increased uterus weight and increased uterine luciferase activity, while the effect of LY117018 on uterus weight and luciferase activity was modest and significantly lower than the effect of $\mathrm{OE}_{2}$. LY117018 and $\mathrm{OE}_{2}$ treatment resulted in similar luciferase activation in thymus. However, only $\mathrm{OE}_{2}$ treatment resulted in thymic atrophy, while no effect on thymus weight was seen after LY117018 treatment. In summary, the raloxifene analogue LY117018 can activate the classical oestrogen pathway in bone, uterus and thymus in vivo, and this activation is associated with BMD and uterus weight, but not thymus weight.

Journal of Endocrinology (2009) 203, 349-356

\section{Introduction}

Oestrogens are of importance for many functions in the body including regulation of the female reproductive system, skeletal growth and bone metabolism, and the immune system.

Oestrogens affect gene transcription in target cells via two main mechanisms, the classical and the non-classical pathway. In the classical pathway, oestrogens bind oestrogen receptors, $\alpha(E R \alpha$; ESR 1 as listed in the MGI Database) or $\beta$ (ER $\beta$; ESR2 as listed in the MGI Database), belonging to the nuclear hormone receptor superfamily (Green et al. 1986, Kuiper et al. 1996). The oestrogen-ER complexes form dimers and translocate into the cell nucleus where it interacts with oestrogen response elements (EREs), located in promoter regions of target genes to initiate gene transcription (Pettersson et al. 1997). The oestrogen-ER complex can also interact with other transcription factors, such as $A p 1, S p 1$ and $N f k b$ (listed as $N f k b$ in the MGI Database), and initiate transcription without binding directly to DNA via the non-classical pathways (Galien \& Garcia 1997, Kushner et al. 2000). Oestrogens have been demonstrated to affect gene transcription in oestrogen-responsive organs, such as bone and uterus, via both classical and non-classical signalling pathways (Ciana et al. 2001, Jakacka et al. 2002, Syed et al. 2005, Windahl et al. 2007).

Raloxifene is a selective ER modulator (SERM) approved to prevent and treat osteoporosis in postmenopausal women, and in the US, it is also approved as prophylaxis against invasive breast cancer in postmenopausal women (Stefanick 2005). It is selective by having agonistic oestrogenic effects on blood lipids and bone formation (Sato et al. 1995), while it has antagonistic effects on reproductive tissues (Black et al. 1994, Cummings et al. 1999). Raloxifene binds both $\mathrm{ER} \alpha$ and $\mathrm{ER} \beta$ (Glasebrook et al. 1993, Gize et al. 1997), and the importance of ERs for the physiological effects of raloxifene has been demonstrated in various cell types using the selective ER antagonist ICI182.780 (Ashby et al. 1997, Viereck et al. 2003). The interaction between raloxifene and ER causes structural differences in the 
complex compared with the oestrogen-ER complex (Bryant et al. 1999), and these structural differences result in assembly of other coregulators (Cheskis et al. 1997), which causes the tissue-specific agonistic/antagonistic effects of raloxifene.

By which signalling pathway raloxifene mediates its oestrogen-like effects in various tissues is still not clearly understood. Most previous studies on how raloxifene exerts its effects have been performed in vitro. Several studies have reported lack of raloxifene signalling via ERE in uterine cancer cell lines. Instead, the non-classical pathway, involving Ap1, is suggested to be more important in these cells (Paech et al. 1997, Cheung et al. 2003). In cultured osteoblasts, it has also been demonstrated that raloxifene may not initiate transcription via the classical pathway (Yang et al. 1996b).

From a public health point of view, oestrogen has positive effects such as being bone preserving, but also negative effects, such as increasing the risk for breast cancer. To be able to understand the mechanisms behind these diverse effects, it is important to know by which intracellular pathways oestrogen and SERMs mediate their biological effects. Since oestrogen and SERM signalling is found to be cell type and cell context specific, it is important to study the signalling of these compounds in vivo.

To investigate whether raloxifene affects gene transcription in the oestrogen-responsive tissues, bone, uterus and thymus via the classical oestrogen pathway, we have used a transgenic $3 \times$ ERE-TAT-Luc (ERE-luciferase) mouse model that transcribes luciferase after binding of a ligand-bound ER to ERE (Lemmen et al. 2004).

\section{Material and Methods}

\section{Animals and experimental procedures}

The studies were performed on transgenic $3 \times$ ERE-TATLuc (ERE-luciferase) mice, on a mixed CBA $\times$ C56Bl/6J background (Lemmen et al. 2004). These mice have a luciferase reporter gene under the control of three consensus EREs coupled to a minimal TATA-box. ER binding to the EREs results in transcription of the enzyme luciferase, and the amount of transcription can subsequently be estimated using an enzymatic reaction (see protein preparation and luciferase analysis) enabling in vivo detection of classical oestrogen signalling. The ethical committee for animal experiments at Gothenburg University approved this study. Mice were kept, five to ten animals per cage, under standard environmental conditions, and fed standard laboratory chow and tap water ad libitum. Ovariectomy (ovx) operations were performed at 3 months of age through a midline incision of the skin and flank incision of the peritoneum. The skin incision was closed with metallic clips. Sham-operated animals had their ovaries exposed but not removed. Surgery was performed after the mice were anaesthetized with ketamine (Pfizer AB, Täby, Sweden) and medetomidine (OrionPharma, Espoo, Finland). Carprofen (OrionPharma) was used post-operatively as a painkiller. At termination, the mice were anaesthetized for blood withdrawal and then killed by cervical dislocation.

\section{Treatment}

Short-term experiment Ovx mice were injected with a single s.c. dose of the raloxifene analogue LY117018 $(60 \mu \mathrm{g} /$ mouse, generous gift from Eli Lilly), raloxifene (raloxifene hydrochloride, $60 \mu \mathrm{g} /$ mouse, Sigma, R1202$500 \mathrm{MG}), 17 \beta$-oestradiol $\left(\mathrm{OE}_{2}\right)-3$-benzoate $(1 \cdot 0 \mu \mathrm{g} / \mathrm{mouse}$, Sigma) or vehicle (Miglyol812 OmyaPeralta $\mathrm{GmbH}$, Hamburg, Germany), 2 weeks after ovx and were thereafter terminated $10 \mathrm{~h}$ after injection. LY117018 differs from raloxifene at one position on the molecule with a piperidine ring on the basic side chain instead of a pyrrolidine ring and was therefore compared with raloxifene to determine whether the two compounds affect classical signalling differently. Sham-operated mice were injected with raloxifene (60 $\mu \mathrm{g} /$ mouse, Sigma) or vehicle (Miglyol812 OmyaPeralta $\mathrm{GmbH})$ and terminated $10 \mathrm{~h}$ after the injection.

Long-term experiment To compare the activation of the classical oestrogen-signalling pathway with physiological effects mediated via oestrogen and the raloxifene analogue LY117018, mice were given s.c. injections for 3 weeks of LY117018 (60 $\mu \mathrm{g} / \mathrm{mouse}$ per day, 5 days per week) or $\mathrm{OE}_{2}-3-$ benzoate $(1 \cdot 0 \mu \mathrm{g} /$ mouse per day, 5 days per week) or vehicle. Treatment started 2 weeks after surgery.

\section{Tissue collection}

Organs (thymus and uterus) were collected and individually frozen in liquid nitrogen. Bone marrow was flushed from the bone cavity of one femur with $5 \mathrm{ml} \mathrm{PBS}$, after detachment of the distal and proximal parts, and centrifuged $(515 \mathrm{~g}, 5 \mathrm{~min}$ ). The supernatant was removed, and the pelleted bone marrow cells were frozen. The cortical bone shafts remaining after removing the bone marrow were also frozen.

\section{Protein preparation and luciferase analysis}

Cortical bone was cut into small pieces using a scalpel prior to homogenization. The frozen tissues were homogenized, using a polytron (Pt 3100, model 27137059) in lysis buffer (25 mM Tris $\mathrm{pH} 7 \cdot 8,1.5 \mathrm{mM}$ EDTA, 10\% glycerol, $1 \%$ Triton X-100, $2 \mathrm{mM}$ dithiothreitol and complete protease inhibitors, \#1535101, Roche), and separated by centrifugation at $10650 \mathrm{~g}$ for $30 \mathrm{~min}$. The supernatant was stored at $-20^{\circ} \mathrm{C}$ until further analysis. Luciferase activation, measured as amount of emitted light in the luciferase assay, is proportional to the activation of gene transcription by ERs binding to the ERE and is therefore considered a measure of signalling via the classical pathway. Luciferase activity in preparations from bone, uterus and thymus was measured and related to the amount of protein. The luciferase activity was analysed using a standard Luciferase Assay (\#E4030, Promega) 
according to the manufacturer's instructions and measured on a GloMax 20/20 Luminometer (\#E5311, Promega). The protein content was measured using BioRad DC protein assay (\#500-0116, Promega), according to the manufacturer's instructions.

\section{Assessment of bone mineral density}

One femur from the long-term experiment was subjected to a peripheral quantitative computed tomography (pQCT) scan with a Stratec pQCT XCT Research M, software version 5.4B (Norland, Fort Atkinson, WI, USA) at a resolution of $70 \mu \mathrm{m}$, as previously described (Windahl et al. 1999). Trabecular bone mineral density (BMD) was determined with a metaphyseal scan at a point 3\% of the length of the femur from the growth plate. The inner $45 \%$ of the area was defined as the trabecular bone compartment. Cortical BMD was determined with a mid-diaphyseal scan.

\section{Real-time PCR analysis}

RNA was isolated from the homogenate of femur, thymus and uterus from ovx animals treated with vehicle, $\mathrm{OE}_{2}$ or raloxifene (short-term treatment, see treatment) using the RNeasy kit (Qiagen). Real-time PCR analyses were performed using the ABI Prism 7700 Sequence Detection System (PE Applied Biosystems, Stockholm, Sweden) and using Assay-on-Demand primer and probe sets (PE Applied Biosystems), labelled with the reporter fluorescent dye FAM. Predesigned primers and a probe labelled with the reporter fluorescent dye VIC, specific for $18 \mathrm{~S}$ rRNA, were included in the reaction as an internal standard. The assay identification numbers were Mm01228180_m1 for insulin-like growth factor-1 (IGF1) and Mm00487425_m1 for c-fos. The amount of mRNA for each gene was calculated using a standard curve method following the manufacture's instructions (PE Applied Biosystems) and adjusted of 18s rRNA.

\section{Statistical analysis}

Values are given as mean \pm s.D. For statistical evaluation, the non-parametric Kruskal-Wallis followed by $\chi^{2}$ post test was used when comparing more than two groups, and when two groups were compared, the Mann-Whitney test was used. A $P$ value $\leq 0.05$ was considered significant.

\section{Results}

Since LY117018, a raloxifene analogue, differs from raloxifene at one position with a piperidine ring on the basic side chain instead of a pyrrolidine ring, the efficacy of these two compounds in regards to activation of the classical signalling pathway was determined. Short-term treatment of raloxifene and raloxifene analogue induced similar stimulation of luciferase activation compared with vehicle control in all three organs investigated (Table 1), showing that these two compounds do not differ in their ability to activate classical oestrogen signalling.

Since raloxifene has known antagonistic effects in some specific organs, e.g. uterus, and inhibits oestrogenic effects, luciferase activity after raloxifene treatment was examined in sham-operated animals. In bone and uterus, we did not detect any significant effects on luciferase activation after raloxifene treatment in sham-operated animals compared with vehicle treatment, while a significant upregulation of classical signalling was seen in thymus $(+205 \% P<0 \cdot 01$ MannWhitney, data not shown).

The raloxifene analogue LY117018 and $\mathrm{OE}_{2}$ have equipotent effects on BMD, and both compounds activate the classical pathway in bone

To compare the activation of the classical oestrogensignalling pathway with physiological effects mediated via oestrogen and the raloxifene analogue LY117018, mice were given s.c. injections for 3 weeks. Treatment of ovx mice with $\mathrm{OE}_{2}$ resulted in increased total BMD compared with vehicle treatment, as measured using pQCT $(+130 \% \quad P<0 \cdot 01$; Fig. 1a and b). A similar increase was seen after treatment with LY117018 (+128\% P<0.01). When determining cortical effects, both $\mathrm{OE}_{2}$ as well as LY117018 treatment increased BMD $(2 \cdot 8$ and $3 \cdot 2 \%$ respectively), bone mineral content (BMC; $10 \cdot 7$ and $16 \cdot 2 \%$ respectively) and cortical

Table 1 Effects of oestradiol, raloxifene or the raloxifene analogue LY117018 on three oestrogen-responsive organs after short- and long-term treatment ${ }^{\mathrm{a}}$. Results are presented as mean \pm S.D

\begin{tabular}{|c|c|c|c|c|}
\hline & \multicolumn{2}{|c|}{ Short-term (10 h) } & \multicolumn{2}{|c|}{ Long-term (3 weeks) } \\
\hline & Raloxifene & $\begin{array}{l}\text { Raloxifene analogue } \\
\text { LY117018 }\end{array}$ & Oestradiol & $\begin{array}{l}\text { Raloxifene analogue } \\
\text { LY117018 }\end{array}$ \\
\hline Uterus & $30 \pm 20^{*}$ & $20 \pm 13^{*}$ & $120 \pm 53^{+}$ & $30 \pm 12$ \\
\hline Bone & $9 \pm 4^{*}$ & $9 \pm 3^{*}$ & $1900 \pm 1600^{+}$ & $430 \pm 230^{*}$ \\
\hline Thymus & $8 \pm 4 *$ & $4 \pm 2 *$ & $20 \pm 20^{+}$ & $9 \pm 5^{*}$ \\
\hline
\end{tabular}

a Luciferase activation in three oestrogen-responsive organs (uterus, bone and thymus) was analysed and related to protein as a measure of the classical oestrogen signalling. The luciferase activation is presented as fold increase compared with vehicle-treated mice.

$*<0 \cdot 05,{ }^{+}<0 \cdot 01$, versus vehicle, Kruskal-Wallis test followed by a $\chi^{2}$ post test $(n=5-8)$. 
(a)
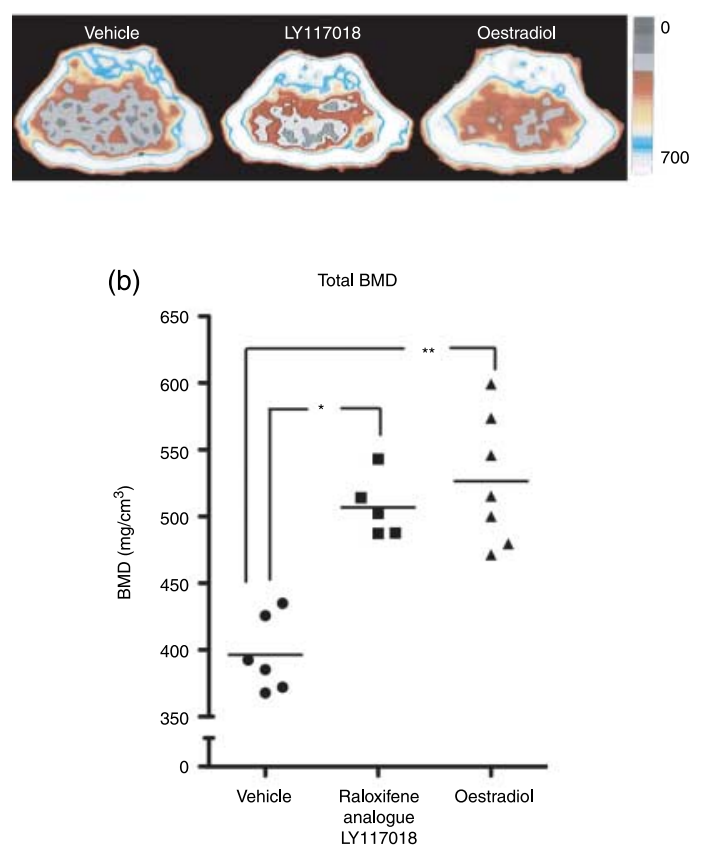

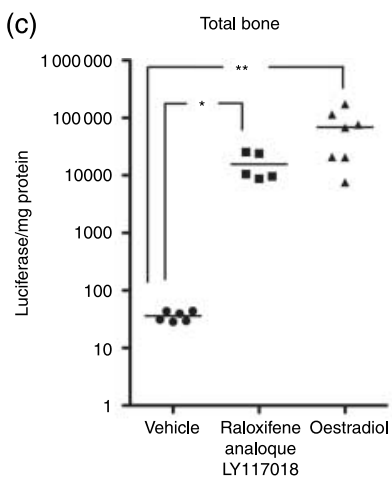

(e)

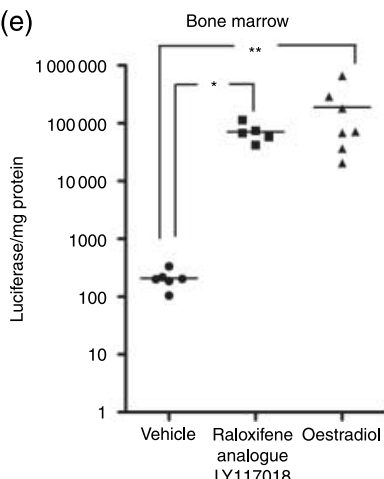

\section{(d)}

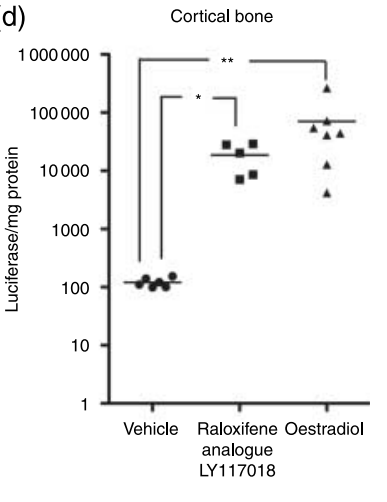

Figure 1 Treatment with the raloxifene analogue LY117018 or oestradiol increases bone mineral density (BMD) and activates classical signalling in total bone, cortical bone and bone marrow. Three-month-old ERE-luciferase mice were ovariectomized and treated with vehicle, raloxifene analogue (LY117018) or oestradiol for 3 weeks. Luciferase activity related to amount of protein is considered a measurement of classical signalling. (a) Representative peripheral quantitative computer tomography images of cross section of the femur showing BMD. The scale indicates the density of the bone, from 0 (black) to $750 \mathrm{mg} / \mathrm{cm}^{3}$ (white). (b) Scatter plots of individual data (bars indicate the mean per group) showing the total BMD. ${ }^{* *} P<0 \cdot 01$, Kruskal-Wallis test followed by a $\chi^{2}$ post test. Scatter plots of individual data (bars indicate the mean per group) showing luciferase activity in (c) total bone, (d) cortical bone and (e) bone marrow. ${ }^{*} P<0 \cdot 05,{ }^{* *} P<0 \cdot 01$, Kruskal-Wallis test followed by a $\chi^{2}$ post test.

thickness $(8 \cdot 4$ and $11 \cdot 4 \%$ respectively) as compared with vehicle treatment (Table 2). Similar effects were also seen regarding trabecular bone, with a $46 \%$ significant increase after $\mathrm{OE}_{2}$ treatment and a $36 \%$ increase $(P=0.052$, MannWhitney) after LY117018 treatment as compared with vehicle (Table 2).

Both $\mathrm{OE}_{2}$ and LY117018 increased luciferase activity significantly as compared with vehicle treatment (Fig. 1c-e). The luciferase activation of $\mathrm{OE}_{2}$ was two- to four-fold greater compared with LY117018 in the bone preparations; however, these differences did not reach statistical significance.

The raloxifene analogue LY117018 has modest effects on both uterus weight and activation of the classical pathway compared with $\mathrm{OE}_{2}$

$\mathrm{OE}_{2}$ treatment of ovx mice resulted in increased uterus weight (tenfold) and luciferase activity (120-fold) compared with vehicle treatment (Fig. $2 \mathrm{a}$ and b). Treatment with the raloxifene analogue LY117018 increased luciferase activity (30-fold) in uterus compared with vehicle treatment (Fig. 2b), and a tendency to increased uterus weight was also seen. However, the effects of LY117018 on both weight and luciferase activation were significantly smaller compared with the effects of $\mathrm{OE}_{2}(P<0 \cdot 05)$.

Raloxifene analogue LY117018 does not induce thymic atrophy, but activates the classical pathway in thymus

As expected, treatment with $\mathrm{OE}_{2}$ induced significant involution of the thymus, as demonstrated by weight reduction $(-46 \%)$ compared with vehicle treatment (Fig. 3a). In contrast, no significant effect of the raloxifene analogue LY117018 treatment was found on thymus weight compared with vehicle treatment. Interestingly, both $\mathrm{OE}_{2}$ and LY117018 treatment resulted in significantly increased luciferase activity in thymus (Fig. 3b), and no significant difference was found between the two treatment groups. 
Table 2 Effects of oestradiol and the raloxifene analogue LY117018 on bone parameters ${ }^{\mathrm{a}}$. Result are presented as mean \pm S.D

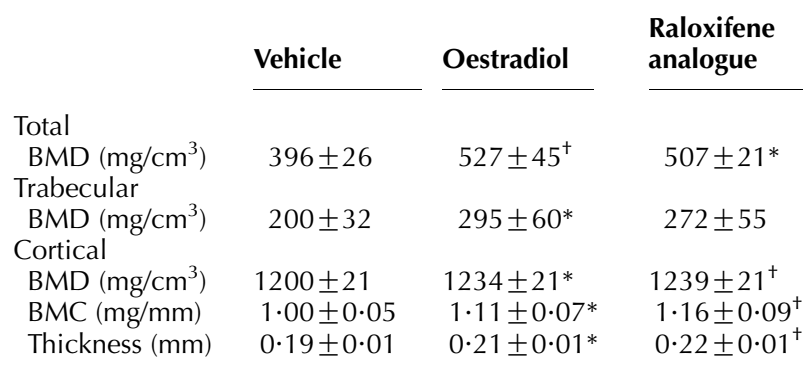

aThe femur from the long-term treatment ( 3 weeks) was analysed with peripheral quantitative computed tomography ( $\mathrm{pQCT}$ ) to measure total, trabecular and cortical bone mineral density (BMD), and cortical bone mineral content $(\mathrm{BMC})$ and thickness.

${ }^{*} P<0 \cdot 05,{ }^{+} P<0 \cdot 01$, versus vehicle, Kruskal-Wallis test followed by a $\chi^{2}$ post test $(n=5-7)$.

\section{$\mathrm{OE}_{2}$ and raloxifene effects via non-classical pathways}

Real-time PCR analyses of homogenates of uterus, bone and thymus was performed from mice treated with $\mathrm{OE}_{2}$, raloxifene or vehicle $10 \mathrm{~h}$ prior to termination (short-term treatment). The non-classical oestrogen pathways were investigated by examining transcription of Igf1, reflecting Ap1 signalling (Umayahara et al. 1994) and c-fos reflecting transcription activated via phosphorylation cascades (Duan et al. 2001).

In uterus, both $\mathrm{OE}_{2}$ and raloxifene treatment increased IGFI expression compared with vehicle treatment (99-fold, $P<0 \cdot 001$ and 16 -fold, $P<0 \cdot 05$ respectively; Table 3 ). The expression of $c$-fos (listed as fos in the MGI Database) mRNA was significantly higher after $\mathrm{OE}_{2}$ treatment compared with vehicle treatment (ninefold, $p<0 \cdot 05$ ), while no significant effect of raloxifene was detected (Table 3). In bone, IgfI expression was not significantly affected by neither $\mathrm{OE}_{2}$ nor raloxifene; however, c-fos expression was significantly altered $(-42 \%, P<0 \cdot 05)$ by $\mathrm{OE}_{2}$ compared with vehicle, while raloxifene had no effect (Table 3). In thymus, $\mathrm{OE}_{2}$, but not raloxifene, significantly up-regulated the mRNA levels of Igf1 compared with vehicle (twofold, $P<0 \cdot 05$ ), while neither $\mathrm{OE}_{2}$ nor raloxifene had effects on mRNA levels of $c$-fos (Table 3).

\section{Discussion}

Oestrogen and oestrogen-like substances are widely used as contraceptives, as hormone replacement for postmenopausal women and as treatment for certain pathological states such as osteoporosis. Since these therapies are afflicted with certain side effects, it is important to carry out mechanistic studies in order to develop better and more potent substances. Most previous studies on how raloxifene exerts its effects have been performed in vitro. However, since oestrogen and SERM signalling is found to be cell type and cell context specific, we believe that it is necessary to study the signalling of these compounds in vivo. There are two main signalling pathways, (a)
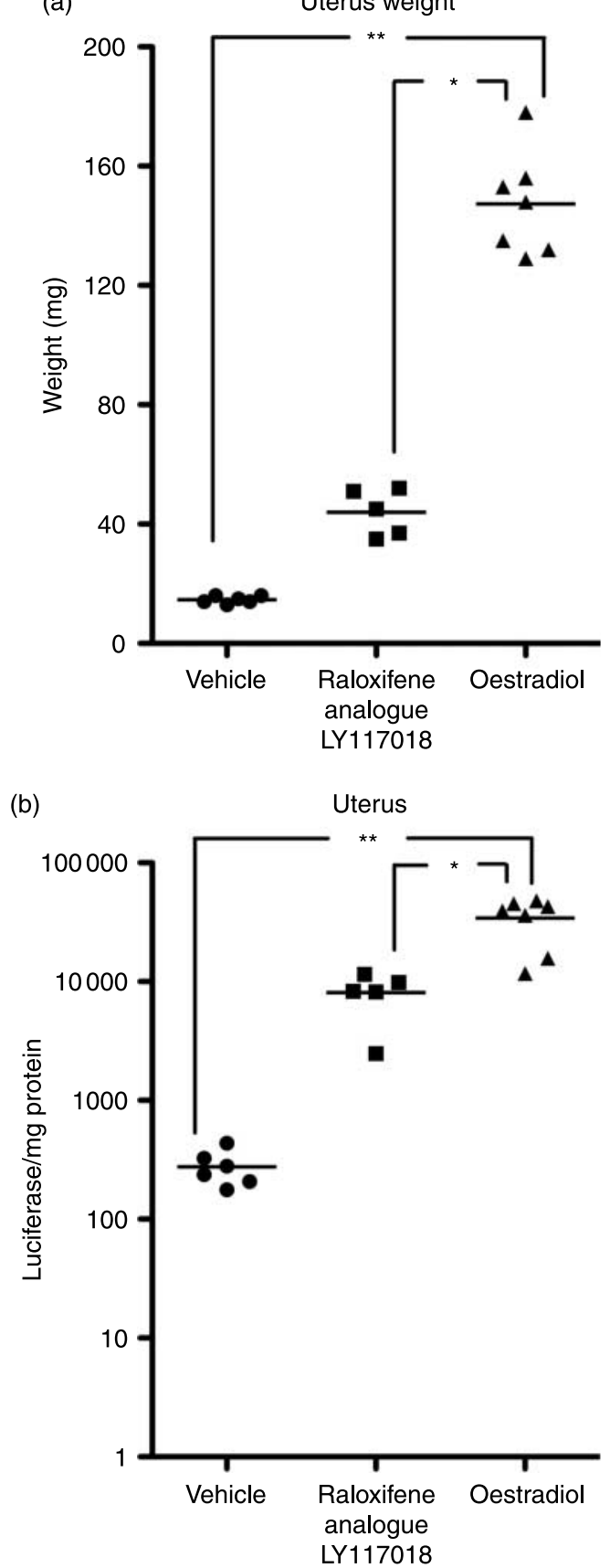

Figure 2 Treatment with the raloxifene analogue LY117018 has modest effects on uterus weight and classical signalling in uterus as compared with oestradiol. ERE-luciferase mice were ovariectomized and treated with vehicle, raloxifene analogue (LY117018) or oestradiol for 3 weeks. Luciferase activity related to amount of protein is considered a measurement of classical signalling. Scatter plots of individual data (bars indicate the mean per group) showing (a) uterus weight and (b) luciferase activity in uterus. ${ }^{*} P<0 \cdot 05,{ }^{* *} P<0 \cdot 01$, Kruskal-Wallis test followed by a $\chi^{2}$ post test. 


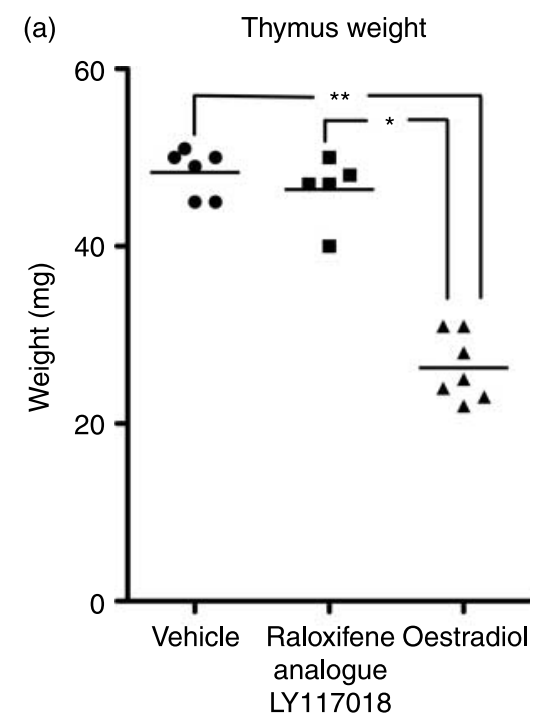

(b)

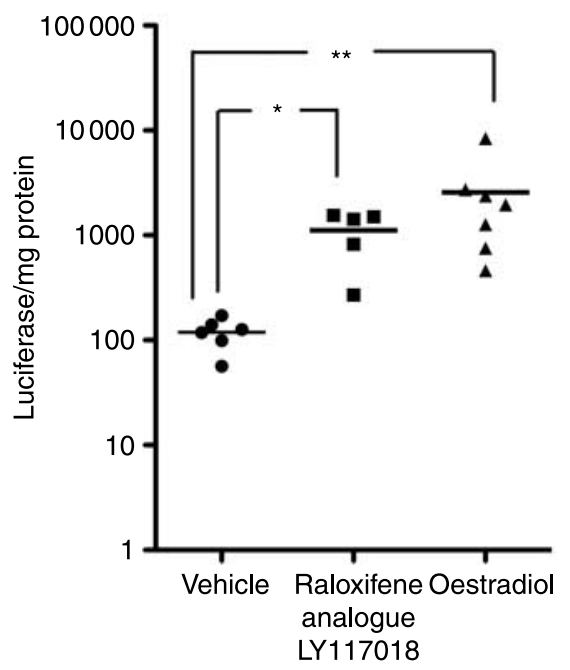

Figure 3 The raloxifene analogue LY117018 does not induce thymic atrophy, but activates the classical pathway in thymus. Thymus weight and luciferase activity related to protein in ovariectomized ERE-luciferase mice after treatment with vehicle, oestradiol or raloxifene analogue (LY117018) for 3 weeks. Scatter plots of individual data (bars indicate the mean per group) showing (a) thymus weight and (b) luciferase activity in thymus. ${ }^{*} P<0 \cdot 05$, ${ }^{* *} P<0 \cdot 01$, Kruskal-Wallis test followed by a $\chi^{2}$ post test.

by which oestrogen can affect gene transcription, the classical involving binding to EREs and the non-classical, which is referred to as ERE independent.

To compare the activation of the classical oestrogensignalling pathway with physiological effects mediated by raloxifene, mice were given s.c. injections of the raloxifene analogue LY117018 for 3 weeks.

In this study, long-term treatment with the raloxifene analogue LY117018 potently increased BMD, and also cortical parameters, such as BMC and thickness to the same extent as $\mathrm{OE}_{2}$, as demonstrated earlier (Erlandsson et al. 2002). This increase in bone mass after LY117018 treatment was accompanied by a significant increase in luciferase activation, demonstrating that a raloxifene analogue can activate the classical oestrogen-signalling pathway in bone in vivo. As previously shown, by our group and others, $\mathrm{OE}_{2}$ was found to activate the classical signalling pathway in bone (Ciana et al. 2003, Windahl et al. 2007). These findings suggest that the classical signalling pathway is involved in the bone-protecting effects of both raloxifene and $\mathrm{OE}_{2}$. It has recently been demonstrated that $\mathrm{OE}_{2}$ also has effect on bone via non-classical signalling pathway by using transgenic mice where ER $\alpha$ is incapable of binding to EREs (Syed et al. 2005, 2007). Furthermore, our finding that c-fos transcription, which is demonstrated to be mediated via phosphorylation cascades, is altered by $\mathrm{OE}_{2}$ in bone further supports involvement of non-classical oestrogen signalling in the regulation of the skeleton. Thus, both classical as well as non-classical signalling seems to be of importance for the effects of $\mathrm{OE}_{2}$ on bone. Raloxifene treatment has, in contrast to our present in vivo data, in previous in vitro studies of cultured osteoblasts, shown no or limited activation of the classical pathway (Yang et al. 1996b). Instead, non-classical pathways have been implicated (Yang et al. 1996a). In our study, looking at gene expression known to be regulated via non-classical oestrogen-signalling pathways, we did not detect any significant effect of raloxifene treatment on the nonclassical signalling pathways we examined. However, our results do not rule out the involvement of other non-classical signalling pathways for the regulation of bone by raloxifene. Thus, our present in vivo data, together with these in vitro studies, suggest that the mechanism(s) by which raloxifene preserves bone may involve both the classical- and the nonclassical signalling pathways. However, the importance of non-classical signalling for the bone protective effects of raloxifene in vivo needs to be further analysed.

Table 3 Real-time PCR after short-term treatment of oestradiol and raloxifene ${ }^{\mathrm{a}}$. Results are presented as mean \pm S.D

\begin{tabular}{|c|c|c|c|}
\hline & Vehicle & Oestradiol & Raloxifene \\
\hline $\begin{array}{l}\text { Uterus } \\
\text { IGF1 } \\
\text { c-fos }\end{array}$ & $\begin{array}{l}0 \cdot 02 \pm 0 \cdot 01 \\
0 \cdot 12 \pm 0 \cdot 06\end{array}$ & $\begin{array}{l}2 \cdot 07 \pm 0 \cdot 77^{+} \\
1 \cdot 11 \pm 0 \cdot 44^{*}\end{array}$ & $\begin{array}{l}0 \cdot 34 \pm 0 \cdot 40^{*} \\
0 \cdot 40 \pm 0 \cdot 36\end{array}$ \\
\hline $\begin{array}{l}\text { Bone } \\
\text { IGF1 } \\
\text { c-fos }\end{array}$ & $\begin{array}{c}1 \cdot 9 \pm 2 \cdot 9 \\
40 \pm 23\end{array}$ & $\begin{array}{c}3 \cdot 4 \pm 3 \cdot 5 \\
23 \pm 8^{*}\end{array}$ & $\begin{array}{c}2 \cdot 6 \pm 2 \cdot 5 \\
27 \pm 17\end{array}$ \\
\hline $\begin{array}{c}\text { Thymus } \\
\text { IGF1 } \\
\text { c-fos }\end{array}$ & $\begin{array}{l}0 \cdot 51 \pm 0 \cdot 28 \\
1 \cdot 12 \pm 0.72\end{array}$ & $\begin{array}{l}0 \cdot 96 \pm 0 \cdot 42^{*} \\
1 \cdot 20 \pm 1 \cdot 13\end{array}$ & $\begin{array}{l}0 \cdot 81 \pm 0 \cdot 42 \\
0 \cdot 71 \pm 0 \cdot 40\end{array}$ \\
\hline
\end{tabular}

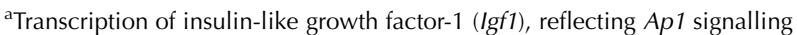
and $c$-fos expression reflecting transcription activated via phosphorylation cascade, was analysed using real-time PCR in uterus, bone and thymus in a short-term experiment.

${ }^{*} P<0 \cdot 05,{ }^{+} P<0 \cdot 001$, versus vehicle, Kruskal-Wallis test followed by a $\chi^{2}$ post test $(n=5-8)$. 
Raloxifene antagonizes oestrogen-induced stimulation of uterine weight gain via pharmacological competition for the ERs (Bryant et al. 1996). Furthermore, raloxifene has been proposed to have antagonistic effects in uterus in shamoperated mice (Erlandsson et al. 2002); however, we did not detect any antagonistic effect on classical signalling by raloxifene in uterus. We therefore suggest that antagonistic effects on uterus mediated by raloxifene may be mediated via other non-classical signalling pathways.

As shown in this study and others, raloxifene has mild agonistic effects on uterine weight in oestrogen-deprived states, and the mechanisms behind these agonistic effects are not completely understood (Black et al. 1994, Erlandsson et al. 2002). We demonstrate here that raloxifene can activate the classical signalling pathway in vivo in uterus. These data are contradictory to previous in vitro studies where uterine cancer cell lines show lack of raloxifene signalling via the classical pathway (Paech et al. 1997, Cheung et al. 2003), and $\mathrm{OE}_{2^{-}}$ induced proliferation of uterine epithelial cells is shown to be independent of the classical pathway (O'Brien et al. 2006). Our analysis of IgfI expression, which is mediated via Ap1, supports the involvement of non-classical signalling in the regulation of the uterus by both $\mathrm{OE}_{2}$ and raloxifene. Thus, both classical and non-classical signalling may be involved in regulation of uterine growth in vivo; however, the relative importance of these signalling pathways for the in vivo effects in uterus needs further investigation.

In thymus, an organ important for the immune system, $\mathrm{OE}_{2}$ treatment results in involution (Erlandsson et al. 2000). In addition, oestrogenic compounds, including raloxifene, have also been reported to result in variable degree of thymic atrophy (Buelke-Sam et al. 1998, Erlandsson et al. 2000, Yellayi et al. 2002, Garcia-Perez et al. 2006). In our study, $\mathrm{OE}_{2}$ resulted in a dramatic decrease in thymus weight, while no thymic atrophy was detected after treatment with the raloxifene analogue LY117018. The inconsistency between our study and previous studies might be dependent on different doses used and different administration routes. However, when comparing $\mathrm{OE}_{2}$ and raloxifene analogue effects, a significant difference between the two compounds is found in regards to thymic weight (Erlandsson et al. 2000, Garcia-Perez et al. 2006), with $\mathrm{OE}_{2}$ being the most potent compound, supporting our data. Interestingly, when examining the capacity to activate the classical oestrogenic pathway, both $\mathrm{OE}_{2}$ and raloxifene resulted in a significant increase in luciferase activation. Thus, there is a discrepancy between treatment effects on thymus weight and activation of the classical signalling pathway. Raloxifene is known to affect $\mathrm{T}$ cell differentiation and various $\mathrm{T}$ cell subpopulation (Erlandsson et al. 2000), effects that are not necessarily reflected by thymic weight. Thus, these raloxifene effects may be mediated via classical signalling. These data also indicate that the $\mathrm{OE}_{2}$ induced thymic involution is not only dependent on the effects of the classical pathway. Instead, the involution of thymus by $\mathrm{OE}_{2}$ may be, at least partly, mediated via non-classical signalling or nongenomic, membrane-associated pathways. Supporting this assumption is our finding that $\mathrm{OE}_{2}$ up-regulated $I g f I \mathrm{mRNA}$ in thymus. Since oestrogenic effects on IgfI transcription are shown to be mediated via Ap1 (Umayahara et al. 1994), our data indicate that non-classical signalling pathway via $A p 1$ could be of importance for thymic involution. Furthermore, signalling via GPR30, a putative membrane-bound ER, induces thymic atrophy and apoptosis of a subpopulation of double-negative thymocytes (Wang et al. 2007).

Since LY117018 differs from raloxifene at one position with a piperidine ring on the basic side chain instead of a pyrrolidine ring, the efficacy of these two compounds in regards to activation of the classical signalling pathway was determined in a short-term experiment. We showed similar effects of the raloxifene analogue and raloxifene regarding activation of the classical signalling pathway in this short-term experiment. However, we cannot rule out differences in nonERE-dependent genomic effects initiated by interactions between transcription factors and ligand-bound ERs between raloxifene and raloxifene analogue. Similarly, differences between the raloxifene analogue and $\mathrm{OE}_{2}$ regarding indirect and non-ERE-dependent genomic effects cannot be ruled out and need further investigation.

In conclusion, since oestrogen has both positive as well as negative physiological effects, it is important to know by which intracellular pathways oestrogen and SERMs, such as raloxifene, mediate their biological effects in various organs. We have demonstrated in vivo that raloxifene can activate the classical oestrogen-signalling pathway in the oestrogenresponsive tissues, bone, uterus and thymus.

\section{Declaration of interest}

C E, C J, P T van der S, H C and $\mathrm{M} \mathrm{K} \mathrm{L}$ have nothing to declare. $\mathrm{J}-\AA \mathrm{G}$ consults for and has equity interests in Karobio AB.

\section{Funding}

The Medical Faculty of Göteborg University (ALFGBG-11201, 2008), the Göteborg Medical Society (GLS-9338, 2007), Swedish Research Council (521-2007-4602, 2007), King GustavV's 80 years' foundation (FAI20080023) and the Association against Rheumatism (R-32671, 2008).

\section{Acknowledgements}

We thank Malin Erlandsson, Anette Hansevi and Charlotta Uggla for excellent technical assistance.

\section{References}

Ashby J, Odum J \& Foster JR 1997 Activity of raloxifene in immature and ovariectomized rat uterotrophic assays. Regulatory Toxicology and Pharmacology 25 226-231.

Black LJ, Sato M, Rowley ER, Magee DE, Bekele A, Williams DC, Cullinan GJ, Bendele R, Kauffman RF, Bensch WR et al. 1994 Raloxifene 
(LY139481 HCI) prevents bone loss and reduces serum cholesterol without causing uterine hypertrophy in ovariectomized rats. Journal of Clinical Investigation 93 63-69.

Bryant HU, Glasebrook AL, Yang NN \& Sato M 1996 A pharmacological review of raloxifene. Journal of Bone and Mineral Metabolism 14 1-9.

Bryant HU, Glasebrook AL, Yang NN \& Sato M 1999 An estrogen receptor basis for raloxifene action in bone. Journal of Steroid Biochemistry and Molecular Biology 69 37-44.

Buelke-Sam J, Cohen IR, Wierda D, Griffey KI, Fisher LF \& Francis PC 1998 The selective estrogen receptor modulator, raloxifene: a segment II/III delivery study in rats. Reproductive Toxicology 12 271-288.

Cheskis BJ, Karathanasis S \& Lyttle CR 1997 Estrogen receptor ligands modulate its interaction with DNA. Journal of Biological Chemistry 272 11384-11391.

Cheung J, Mak YT, Papaioannou S, Evans BA, Fogelman I \& Hampson G 2003 Interleukin-6 (IL-6), IL-1, receptor activator of nuclear factor kappaB ligand (RANKL) and osteoprotegerin production by human osteoblastic cells: comparison of the effects of 17-beta oestradiol and raloxifene. Journal of Endocrinology 177 423-433.

Ciana P, Di Luccio G, Belcredito S, Pollio G, Vegeto E, Tatangelo L, Tiveron C \& Maggi A 2001 Engineering of a mouse for the in vivo profiling of estrogen receptor activity. Molecular Endocrinology 15 1104-1113.

Ciana P, Raviscioni M, Mussi P, Vegeto E, Que I, Parker MG, Lowik C \& Maggi A 2003 In vivo imaging of transcriptionally active estrogen receptors. Nature Medicine 9 82-86.

Cummings SR, Eckert S, Krueger KA, Grady D, Powles TJ, Cauley JA, Norton L, Nickelsen T, Bjarnason NH, Morrow M et al. 1999 The effect of raloxifene on risk of breast cancer in postmenopausal women: results from the MORE randomized trial. Multiple Outcomes of Raloxifene Evaluation. Journal of the American Medical Association 281 2189-2197.

Duan R, Xie W, Burghardt RC \& Safe S 2001 Estrogen receptor-mediated activation of the serum response element in MCF-7 cells through MAPK-dependent phosphorylation of Elk-1. Journal of Biological Chemistry 276 11590-11598.

Erlandsson MC, Gomori E, Taube M \& Carlsten H 2000 Effects of raloxifene, a selective estrogen receptor modulator, on thymus, $\mathrm{T}$ cell reactivity, and inflammation in mice. Cellular Immunology 205 103-109.

Erlandsson MC, Jonsson CA, Lindberg MK, Ohlsson C \& Carlsten H 2002 Raloxifene- and estradiol-mediated effects on uterus, bone and $\mathrm{B}$ lymphocytes in mice. Journal of Endocrinology 175 319-327.

Galien R \& Garcia T 1997 Estrogen receptor impairs interleukin-6 expression by preventing protein binding on the NF-kappaB site. Nucleic Acids Research 25 2424-2429.

Garcia-Perez MA, Del Val R, Noguera I, Hermenegildo C, Pineda B, Martinez-Romero A \& Cano A 2006 Estrogen receptor agonists and immune system in ovariectomized mice. International Journal of Immunopathology and Pharmacology 19 807-819.

Gize E, Venugopalan M, Glasebrook A \& Yang N 1997 Characterization of raloxifene binding and transactivation properties of the estrogen receptor-beta (ERbeta). Journal of Bone and Mineral Research 12 S460.

Glasebrook A, Phillips D \& Sluka J 1993 Multiple binding sites for the antiestrogen raloxifene (LY156758). Journal of Bone and Mineral Research $8 \mathrm{~S} 268$.

Green S, Walter P, Greene G, Krust A, Goffin C, Jensen E, Scrace G, Waterfield M \& Chambon P 1986 Cloning of the human oestrogen receptor cDNA. Journal of Steroid Biochemistry 24 77-83.

Jakacka M, Ito M, Martinson F, Ishikawa T, Lee EJ \& Jameson JL 2002 An estrogen receptor (ER)alpha deoxyribonucleic acid-binding domain knock-in mutation provides evidence for nonclassical ER pathway signaling in vivo. Molecular Endocrinology 16 2188-2201.

Kuiper GG, Enmark E, Pelto-Huikko M, Nilsson S \& Gustafsson JA 1996 Cloning of a novel receptor expressed in rat prostate and ovary. PNAS 93 5925-5930.

Kushner PJ, Agard DA, Greene GL, Scanlan TS, Shiau AK, Uht RM \& Webb P 2000 Estrogen receptor pathways to AP-1. Journal of Steroid Biochemistry and Molecular Biology 74 311-317.
Lemmen JG, Arends RJ, van Boxtel AL, van der Saag PT \& van der Burg B 2004 Tissue- and time-dependent estrogen receptor activation in estrogen reporter mice. Journal of Molecular Endocrinology 32 689-701.

O'Brien JE, Peterson TJ, Tong MH, Lee EJ, Pfaff LE, Hewitt SC, Korach KS, Weiss J \& Jameson JL 2006 Estrogen-induced proliferation of uterine epithelial cells is independent of estrogen receptor alpha binding to classical estrogen response elements. Journal of Biological Chemistry 281 26683-26692.

Paech K, Webb P, Kuiper GG, Nilsson S, Gustafsson J, Kushner PJ \& Scanlan TS 1997 Differential ligand activation of estrogen receptors ERalpha and ERbeta at AP1 sites. Science 277 1508-1510.

Pettersson K, Grandien K, Kuiper GG \& Gustafsson JA 1997 Mouse estrogen receptor beta forms estrogen response element-binding heterodimers with estrogen receptor alpha. Molecular Endocrinology 11 1486-1496.

Sato M, Kim J, Short LL, Slemenda CW \& Bryant HU 1995 Longitudinal and cross-sectional analysis of raloxifene effects on tibiae from ovariectomized aged rats. Journal of Pharmacology and Experimental Therapeutics 272 1252-1259.

Stefanick ML 2005 Estrogens and progestins: background and history, trends in use, and guidelines and regimens approved by the US Food and Drug Administration. American Journal of Medicine 118 64-73.

Syed FA, Modder UI, Fraser DG, Spelsberg TC, Rosen CJ, Krust A, Chambon P, Jameson JL \& Khosla S 2005 Skeletal effects of estrogen are mediated by opposing actions of classical and nonclassical estrogen receptor pathways. Journal of Bone and Mineral Research 20 1992-2001.

Syed FA, Fraser DG, Spelsberg TC, Rosen CJ, Krust A, Chambon P, Jameson JL \& Khosla S 2007 Effects of loss of classical estrogen response element signaling on bone in male mice. Endocrinology 148 1902-1910.

Umayahara Y, Kawamori R, Watada H, Imano E, Iwama N, Morishima T, Yamasaki Y, Kajimoto Y \& Kamada T 1994 Estrogen regulation of the insulin-like growth factor I gene transcription involves an AP-1 enhancer. Journal of Biological Chemistry 269 16433-16442.

Viereck V, Grundker C, Blaschke S, Niederkleine B, Siggelkow H, Frosch KH, Raddatz D, Emons G \& Hofbauer LC 2003 Raloxifene concurrently stimulates osteoprotegerin and inhibits interleukin- 6 production by human trabecular osteoblasts. Journal of Clinical Endocrinology and Metabolism $\mathbf{8 8}$ 4206-4213.

Wang C, Dehghani B, Magrisso IJ, Rick EA, Bonhomme E, Cody DB, Elenich LA, Subramanian S, Murphy SJ, Kelly MJ et al. 2007 GPR30 contributes to estrogen-induced thymic atrophy. Molecular Endocrinology 22 636-648.

Windahl SH, Vidal O, Andersson G, Gustafsson JA \& Ohlsson C 1999 Increased cortical bone mineral content but unchanged trabecular bone mineral density in female ERbeta $(-/-)$ mice. Journal of Clinical Investigation 104 895-901.

Windahl SH, Lagerquist MK, Andersson N, Jochems C, Kallkopf A, Hakansson C, Inzunza J, Gustafsson JA, van der Saag PT, Carlsten H et al. 2007 Identification of target cells for the genomic effects of estrogens in bone. Endocrinology 148 5688-5695.

Yang NN, Bryant HU, Hardikar S, Sato M, Galvin RJ, Glasebrook AL \& Termine JD 1996a Estrogen and raloxifene stimulate transforming growth factor-beta 3 gene expression in rat bone: a potential mechanism for estrogen- or raloxifene-mediated bone maintenance. Endocrinology 137 2075-2084.

Yang NN, Venugopalan M, Hardikar S \& Glasebrook A 1996 Identification of an estrogen response element activated by metabolites of 17 beta-estradiol and raloxifene. Science 273 1222-1225.

Yellayi S, Naaz A, Szewczykowski MA, Sato T, Woods JA, Chang J, Segre M, Allred CD, Helferich WG \& Cooke PS 2002 The phytoestrogen genistein induces thymic and immune changes: a human health concern? PNAS 99 7616-7621.

Received in final form 23 July 2009

Accepted 14 September 2009

Made available online as an Accepted Preprint 14 September 2009 